American Journal of Environmental Sciences 5 (5): 605-609, 2009

ISSN 1553-345X

(C) 2009 Science Publications

\title{
Controlling Ammonia Volatilization by Mixing Urea with Humic Acid, Fulvic Acid, Triple Superphosphate and Muriate of Potash
}

\author{
${ }^{1}$ Shamsuddin Rosliza, ${ }^{1}$ Osumanu Haruna Ahmed and ${ }^{2}$ Nik Muhamad Ab. Majid \\ ${ }^{1}$ Department of Crop Science, Faculty of Agriculture and Food Sciences, \\ University Putra Malaysia Bintulu Campus, 97008 Bintulu, Sarawak, Malaysia \\ ${ }^{2}$ Department of Forest Management, Faculty of Forestry, \\ University Putra Malaysia, 43400 UPM, Serdang, Selangor, Malaysia
}

\begin{abstract}
Problem statement: Inefficient use of inorganic fertilizer such as urea is caused by substantial losses of ammonia when urea is surface-applied. Ammonia losses can be controlled by adding acidic material such as TSP, HA or FA. In order to reduce ammonia loss and retain soil exchangeable ammonium and available nitrate as well as producing complete organic based fertilizer, this study was conducted to compare the effects of urea-TSP-MOP, urea-TSP-MOP-HA, urea-TSPMOP-FA, urea-TSP-MOP-acidified (HA + FA) mixtures on ammonia loss, soil pH, soil exchangeable ammonium and available nitrate accumulation compared to urea alone. Approach: The effects of urea amended with or without TSP, MOP, HA and FA were evaluated in a laboratory condition using a closed-dynamic air flow system. Ammonia loss, soil $\mathrm{pH}$, soil exchangeable ammonium and available nitrate were determined using standard procedures. Results: Urea-TSP-MOP-HA, Urea-TSP-MOP, Urea-TSP-MOP-FA and Urea-TSP-MOP-Acidified (HA + FA) mixtures significantly reduces ammonia loss by $12.92,20.12,29.54$ up to $100 \%$ compared to urea alone. The same observation was made for soil exchangeable ammonium. From all the treatments, only Urea-TSP-MOP-FA and UreaTSP-MOP-Acidified (HA + FA) significantly retained soil available nitrate accumulation and the findings were consistent with $\mathrm{pH}$ found in the study. It must be stressed that results obtained in the incubation experiment using an acidic $\left(\mathrm{pH}_{\text {water }}\right.$ 6.32) soil of Typic Paleudults (Bekenu series) might only be applicable to similar acid soils. Conclusion: Urea, TSP and MOP amended with HA or HA and FA significantly reduced ammonia loss. The outcome of this study may contribute to the improvement of urea $\mathrm{N}, \mathrm{P}$ and $\mathrm{K}$ use efficiency as well as reducing environmental pollution.
\end{abstract}

Key words: Ammonia volatilization, urea, triple superphosphate, muriate of potash, humic acids, fulvic acids, $\mathrm{pH}$, exchangeable ammonium, available nitrate

\section{INTRODUCTION}

Malaysia is the largest producer and exporter of palm oil in the world ${ }^{[1]}$ and this contributes about U\$ 7.3 billion in export earnings each year ${ }^{[2]}$. With such large production of palm oil there is also abundant byproducts such as Palm Oil Mill Effluent (POME). The POME contains high Bio-Chemical Oxygen Demand (BOD) and Chemical Oxygen Demand (COD) which pose a great threat to water environment. Disposal of this highly polluting waste is an economic burden on communities and industries ${ }^{[3]}$ therefore adding value to this waste could be economically viable.

POME could be put into good use in view of its high content of organic matter ${ }^{[1]}$ potentially present in the form of Humic Acids (HA) and Fulvic Acids (FA).
In some studies, acidic material such as HA and TSP have been used to reduce ammonia loss from surfaceapplied urea $\mathrm{a}^{[4-8]}$ but an information such as this is lacking for POME. These acidic materials lower the soil microsite $\mathrm{pH}$ immediately around the fertilizer, reduce the hydrolysis of urea thus reducing the ammonia loss. The use of MOP may help to prevent the deficiency of chlorine under field conditions since chlorine is only very weakly adsorbed to soil colloids ${ }^{[9]}$. High total acidity (CEC) associated with HA aid to retain $\mathrm{NH}_{4}$ and $\mathrm{NO}_{3}{ }^{[4-7]}$ which are the plant usable form of nitrogen. The exchange capacity of FA is more than double that of HA due to the total number carboxyl $(\mathrm{COOH})$ groups present and this is expected to retain more $\mathrm{NH}_{4}$ and $\mathrm{NO}_{3}$. High contents of $\mathrm{NH}_{4}$ and $\mathrm{NO}_{3}$ in the soil without good retention may not guarantee plant

Corresponding Author: Osumanu Haruna Ahmed, Department of Crop Science, Faculty of Agriculture and Food Sciences, University Putra Malaysia Bintulu Campus, Sarawak, Malaysia Tel: +6086855406 Fax: +608685415 
$\mathrm{N}$ use efficiency because both $\mathrm{NH}_{4}$ and $\mathrm{NO}_{3}$ are prone to leaching ${ }^{[9]}$. The additional loss of $\mathrm{N}$ from soil is caused by the biological transformation of $\mathrm{NH}_{4}$ to $\mathrm{NO}_{3}$ under anaerobic condition and denitrification process of converting $\mathrm{NO}_{3}$ to $\mathrm{N}_{2}{ }^{[9]}$. Inefficient use of urea gives impact to economy, waste of money and reduces crop quality. The objective of the study was to compare the effects of urea-TSP-MOP, urea-TSP-MOP-HA, ureaTSP-MOP-FA, urea-TSP-MOP-acidified (HA + FA) on $\mathrm{NH}_{3}$ loss, $\mathrm{pH}$, exchangeable $\mathrm{NH}_{4}$ and available $\mathrm{NO}_{3}$ accumulation with urea alone. This study may improve urea $\mathrm{N}$ use efficiency as well as reducing environmental pollution.

\section{MATERIALS AND METHODS}

The soil used in this study was a sandy loam of typic paleudults (Bekenu series) taken from University Putra Malaysia, Bintulu Sarawak campus. The soil samples taken at $0-15 \mathrm{~cm}$ depth were air dried and ground to pass a $2 \mathrm{~mm}$ sieve. The selected chemical and physical properties of the soil were determined using standard procedures. The soil $\mathrm{pH}$ was determined in a 1:2.5 of soil: Distilled water suspension and $1 \mathrm{M} \mathrm{KCl}$ using a glass electrode. Soil organic carbon was determined by $58 \%$ of the total loss of weight on ignition $^{[10]}$. The hydrometer method was used to determine soil texture ${ }^{[11]}$. The leaching method was used to determine cation exchange capacity. The exchangeable cations (K, $\mathrm{Ca}, \mathrm{Na}$ and $\mathrm{Mg}$ ) were determined by the double acid method. Total $\mathrm{N}$ was determined using Micro-kjedhal method.

HA and FA used in this study were isolated using the method described by Stevenson ${ }^{[12]}$ with some modifications $^{[13]}$. The extraction and fractionation periods used were $24 \mathrm{~h}$. Humic acid and FA was isolated using $0.05 \mathrm{M} \quad \mathrm{KOH}$ and $6 \mathrm{~N} \quad \mathrm{H}_{2} \mathrm{SO}_{4}$, respectively. Total organic carbon was determined using loss on ignition method ${ }^{[10]}$. The carboxylic$\mathrm{COOH}$, phenolic-OH functional groups and total acidity were determined by the method described by Inbar et al. ${ }^{[14]}$. $\mathrm{E}_{4} / \mathrm{E}_{6}$ was determined using $\mathrm{E}_{4} / \mathrm{E}_{6}$ ratio $^{[13]}$. The solid HA and TSP were ground to pass $250 \mu \mathrm{m}$, the MOP was in powder form and the urea was in granules form. Fulvic acid and acidified HA + FA were in liquid form.

The treatments evaluated were:

Soil alone (T0)

$2.02 \mathrm{~g}$ urea without additives (T1)

$2.02 \mathrm{~g}$ urea+1.52 g TSP+1.34 g MOP (T2)
$2.02 \mathrm{~g}$ urea+1.52 g TSP+1.34 g MOP+0.75 g HA (T3)

2.02 g urea+1.52 g TSP+1.34 g MOP+60 mL FA (T4)

$2.02 \mathrm{~g}$ urea+1.52 g TSP+1.34 g MOP+60 mL

Acidified (HA + FA) (T5)

The quantity of urea, TSP and MOP used were based on the standard recommendation for mature oil palms grown on Bungor Series (Typic Kandiudults) in Malaysia. The amounts of HA used were based on earlier unpublished laboratory trials that gave better mixtures. Treatment 2 was prepared by mixing $2.02 \mathrm{~g}$ urea with $1.52 \mathrm{~g}$ TSP and $1.34 \mathrm{~g}$ MOP. Treatment 3 was prepared by mixing $2.02 \mathrm{~g}$ urea with $1.52 \mathrm{~g}$ TSP, $1.34 \mathrm{~g}$ MOP and $0.75 \mathrm{~g}$ HA. Treatment 4 was prepared by mixing $2.02 \mathrm{~g}$ urea with $1.52 \mathrm{~g}$ TSP, $1.34 \mathrm{~g}$ MOP and $60 \mathrm{~mL}$ FA, while T5 was prepared by mixing $2.02 \mathrm{~g}$ urea with $1.52 \mathrm{~g}$ TSP, $1.34 \mathrm{~g}$ MOP and $60 \mathrm{~mL}$ acidified HA and FA. Afterwards, the treatments were transferred into a set of plastic vials, tightly closed and shaken on a reciprocal shaker at $150 \mathrm{rpm}$ for $30 \mathrm{~min}$ to ensure they were uniformly mixed.

Daily ammonia loss was measured for 15 days by the closed-dynamic air flow system method ${ }^{[4]}$. The system consisted of an exchange chamber $(500 \mathrm{~mL}$ Erlenmeyer flask) and a trap $(250 \mathrm{~mL}$ Erlenmeyer flask), both stoppered and fitted with an inlet/outlet. The inlet of the chamber was connected to an air pump and the outlet was connected by polyethylene tubing to the trap containing boric acid solution. The $250 \mathrm{~g}$ of soil that was placed in the exchange chamber was moistened to $60 \%$ field capacity.

The treatments were applied to the soil surface. Air was passed through the chambers at a rate of $2.75 \mathrm{~L}^{-1}$ min $^{-1}$ chamber ${ }^{-1}$ and released $\mathrm{NH}_{3}$ captured in the trapping solution containing $75 \mathrm{~mL}$ boric acid bromocresol green and methyl red indicator. The incubation chambers were maintained at room temperature. Boric acid indicator traps were replaced every $24 \mathrm{~h}$ and back titrated with $0.01 \mathrm{~N} \mathrm{HCl}$, to estimate the $\mathrm{NH}_{3}$ released. Measurement was continued until the loss declined to $1 \%$ of the $\mathrm{N}$ added in the urea ${ }^{[5,7,8]}$. After 15 days of incubation, soil samples were evaluated for $\mathrm{pH}$, exchangeable $\mathrm{NH}_{4}$ and available $\mathrm{NO}_{3}{ }^{[15]}$.

The experimental design was a randomized complete block design with 3 replications for each treatment. Analysis of variance (ANOVA) was conducted to test for treatment effect while means of treatments were compared using Tukey's test ${ }^{[16]}$.

\section{RESULTS}

The chemical and physical characteristics of soil, HA, FA and acidified (HA + FA) are shown in Table 1. 
Am. J. Environ. Sci., 5 (5): 605-609, 2009

Table 1: Some chemical and physical characteristics of soil, HA, FA and acidified (HA + FA)

\begin{tabular}{|c|c|c|c|c|}
\hline Property & Soil & HA & FA & $\begin{array}{l}\text { Acidified } \\
(\mathrm{HA}+\mathrm{FA})\end{array}$ \\
\hline $\mathrm{pH}$ (water) & 6.32 & nd & 1.13 & 1.00 \\
\hline $\mathrm{pH}(1 \mathrm{~N} \mathrm{MOP})$ & 5.52 & nd & nd & nd \\
\hline Total organic carbon $(\%)$ & 4.72 & 54.95 & nd & nd \\
\hline Nitrogen $(\%)$ & 0.17 & nd & nd & nd \\
\hline $\operatorname{CEC}\left(\mathrm{cmol} \mathrm{kg}^{-1}\right)$ & 13.3 & nd & nd & nd \\
\hline Exchangeable $\mathrm{K}\left(\mathrm{cmol} \mathrm{kg}^{-1}\right)$ & 0.18 & nd & nd & nd \\
\hline Exchangeable $\mathrm{Ca}\left(\mathrm{cmol} \mathrm{kg}^{-1}\right)$ & 1.21 & nd & 0.89 & nd \\
\hline Exchangeable $\mathrm{Na}\left(\mathrm{cmol} \mathrm{kg}^{-1}\right)$ & 0.01 & nd & 2.78 & nd \\
\hline Exchangeable $\mathrm{Mg}\left(\mathrm{cmol} \mathrm{kg}^{-1}\right)$ & 0.12 & nd & 0.29 & nd \\
\hline Texture & LS & nd & nd & nd \\
\hline Carboxylic group $\left(\mathrm{cmol} \mathrm{kg}^{-1}\right)$ & nd & 538.81 & nd & nd \\
\hline Phenolic group $\left(\mathrm{cmol} \mathrm{kg}^{-1}\right)$ & nd & 293.89 & nd & nd \\
\hline Total acidity $\left(\mathrm{cmol} \mathrm{kg}^{-1}\right)$ & nd & 832.70 & nd & nd \\
\hline $\mathrm{E}_{4} / \mathrm{E}_{6}$ & nd & 8.02 & nd & nd \\
\hline \multicolumn{5}{|c|}{ 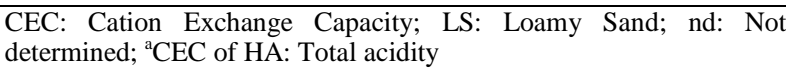 } \\
\hline \multicolumn{5}{|c|}{ Table 2: $\mathrm{pH}$ of urea, TSP and MOP } \\
\hline $\begin{array}{ll}\text { Property } & \text { Urea } \\
\end{array}$ & & TSP & & MOP \\
\hline 8.06 & & 2.89 & & 7.52 \\
\hline
\end{tabular}

The selected chemical properties of the soil were typical of the Typic Paleudults (Bekenu Series) and were consistent with those reported by Paramanathan ${ }^{[17]}$ except for the high values of $\mathrm{pH}$, organic carbon, CEC and exchangeable calcium. The $\mathrm{pH}$ of HA and FA were low. The carbon, carboxylic, phenolic, total acidity and $\mathrm{E}_{4} / \mathrm{E}_{6}$ values of the $\mathrm{HA}$ were within the range reported by some authors ${ }^{[12,18]}$. The $\mathrm{pH}$ of urea was high as expected (Table 2). The $\mathrm{pH}$ of TSP was low and the $\mathrm{pH}$ of MOP was neutral.

Daily loss of ammonia is shown in Fig. 1. Ammonia loss started a day after incubation for urea, three days of incubation for $\mathrm{T} 2, \mathrm{~T} 3$ and $\mathrm{T} 4$ while no loss was found for T5. T2, T3, T4 and T5 reduced the maximum daily rate of loss of ammonia from 13-6.24, $9.18,6.26$ and $0 \%$ (of the $\mathrm{N}$ added as urea) respectively. The maximum ammonia loss for $\mathrm{T} 1$ occurred on the second day, T3 and T4 on the fourth day, $\mathrm{T} 2$ on the seventh day of incubation when the ammonia loss was about $1 \%$ of the $\mathrm{N}$ added as urea. The total amounts of ammonia lost at the end of the incubation period as a percentage of urea- $\mathrm{N}$ were 0 , $48.21,38.51,41.98$ and $0 \%$ for T0, T1, T2, T3, T4 and T5 respectively (Table 3 ).

All the treatments with TSP, MOP, FA, HA significantly reduced ammonia loss compared with urea without additives (T1) with T5 mixture of urea, HA, FA, TSP and MOP having the greatest effect on ammonia loss. Ammonia loss was found to be zero for T0 and T5. No loss for T0 shows the soil does not contribute to ammonia loss in this study. The reduction of ammonia loss was highly related to the significantly low soil $\mathrm{pH}$ obtained for T4 and T5 with significantly highest retention of soil nitrate compared to urea alone.
Table 3: Total amounts of ammonia loss, $\mathrm{pH}$, exchangeable ammonium and available nitrate over 15 days of incubation

\begin{tabular}{lrrrr}
\hline Treatments & $\mathrm{NH}_{3}(\%)$ & $\mathrm{pH}\left(\mathrm{H}_{2} 0\right)$ & $\mathrm{NH}_{4}(\mathrm{ppm})$ & $\mathrm{NO}_{3}(\mathrm{ppm})$ \\
\hline T0 & $0.00^{\mathrm{e}}$ & $6.7^{\mathrm{d}}$ & $81.73^{\mathrm{e}}$ & $11.68^{\mathrm{c}}$ \\
T1 & $48.21^{\mathrm{a}}$ & $7.9^{\mathrm{bc}}$ & $378.27^{\mathrm{d}}$ & $23.35^{\mathrm{c}}$ \\
T2 & $38.51^{\mathrm{c}}$ & $8.4^{\mathrm{ab}}$ & $665.48^{\mathrm{b}}$ & $30.36^{\mathrm{c}}$ \\
T3 & $41.98^{\mathrm{b}}$ & $7.7^{\mathrm{c}}$ & $651.47^{\mathrm{c}}$ & $28.02^{\mathrm{c}}$ \\
T4 & $33.97^{\mathrm{d}}$ & $6.2^{\mathrm{e}}$ & $1169.84^{\mathrm{a}}$ & $123.76^{\mathrm{a}}$ \\
T5 & $0.00^{\mathrm{e}}$ & $2.8^{\mathrm{f}}$ & $546.39^{\mathrm{c}}$ & $58.38^{\mathrm{b}}$ \\
\hline
\end{tabular}

Note: Different alphabets (within column) indicate significant difference between means using Tukey's test at $\mathrm{P}=0.05$

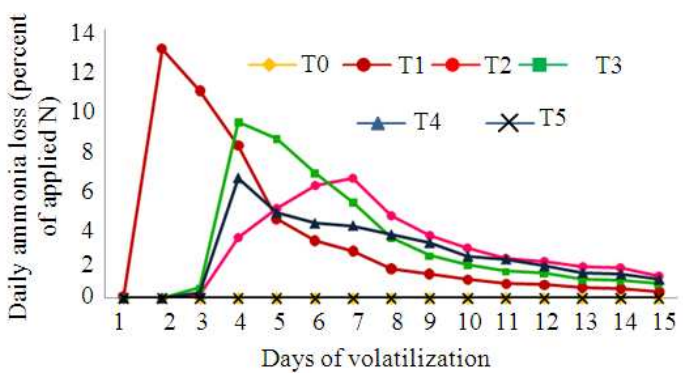

Fig. 1: Daily loss of ammonia from incubation

Soil $\mathrm{pH}$ and nitrate accumulation for $\mathrm{T} 2$ and $\mathrm{T} 3$ was found not significantly different from urea alone.

There was a significant accumulation of soil exchangeable ammonium for all the treatments compare to urea without additives. Exchangeable ammonium retention was twice for $\mathrm{T} 4$ compared to $\mathrm{T} 2, \mathrm{~T} 3$ and T5. Available nitrate accumulation was better for T4 and T5.

\section{DISCUSSION}

The values of $\mathrm{pH}$, organic carbon, CEC and exchangeable calcium in selected chemical properties of the soil were higher compared to those reported by Paramanathan ${ }^{[17]}$ may be due to liming. The low $\mathrm{pH}$ of HA and FA suggests that they were fully saturated with hydrogen ions during their fractionation via acidification using $6 \mathrm{~N} \mathrm{H}_{2} \mathrm{SO}_{4}$. The consistent values of carbon, carboxylic, phenolic, total acidity and $\mathrm{E}_{4} / \mathrm{E}_{6}$ of the HA indicates the purity of the acids.

A rapid loss of ammonia from urea alone was probably due to increased of $\mathrm{pH}$ at the soil microsite as urea hydrolysis leads to consumption of hydrogen ions $\left(\mathrm{H}^{+}\right)$from the soil solution. Removal of more $\mathrm{H}^{+}$ associated with low buffering capacity of soil used in the study, increased the soil $\mathrm{pH}$ and enhanced more formation of $\mathrm{NH}_{4}$ over $\mathrm{NH}_{3}$. The rate of urea hydrolysis for urea-TSP-MOP, urea-TSP-MOP-HA and urea-TSPMOP-FA mixtures were slower by 2 days than volatilization of urea alone because more hydrogen ion contained in phosphoric acid or in the HA and FA's 
functional groups effectively replaced the removed $\mathrm{H}^{+}$ during urea hydrolysis thus aiding in buffering the soil $\mathrm{pH}$ from increasing sharply and slowing down the rate of ammonia volatilization. The greatest effect can be seen from the mixture of urea-TSP-MOP-acidified (HA + FA) whereby the combination of the two acids (HA and FA) together with TSP and MOP significantly slowed the rate of urea hydrolysis by hundred percent. The combination of the two gave such result due to increased number of functional groups embedded in them.

The significant reduction of ammonia volatilization and higher amount of soil exchangeable ammonium for urea-TSP-MOP mixtures was because of phosphoric acid produced by hydrolysis of acidic phosphate. The acid might have acidified the soil microsite and resulted in low $\mathrm{pH}$ that encouraged higher formation of ammonium over ammonia ${ }^{[8]}$.

Urea-TSP-MOP-HA mixtures effectively reduced ammonia loss and retained soil exchangeable ammonium compared to urea alone. The acidic nature and high CEC of HA aided in reduction of ammonia loss and retained soil exchangeable ammonium ${ }^{[4]}$. However, the addition of HA in the urea-TSP-MOP mixtures was not beneficial since the mixtures alone without $\mathrm{HA}$ able to reduce $\mathrm{NH}_{3}$ loss and improved $\mathrm{NH}_{4}$ retention. This may be due to $\mathrm{K}^{+}$contained in the acid that reduce the quantity of $\mathrm{H}^{+}$in the mixtures thus increased soil $\mathrm{pH}$.

The mixtures of urea-TSP-MOP-FA significantly reduced ammonia volatilization with the highest accumulation of soil exchangeable ammonium and available nitrate. The reduction was favored by the addition of both phosphoric acid and FA. The exchange capacity of FA is twice that of HA due to the total number carboxyl $(\mathrm{COOH})$ groups present and this helped to hold more exchangeable ammonium from converting to ammonia. The significantly low $\mathrm{pH}$ retarded the urea hydrolysis in the soil microsite immediately around the fertilizer ${ }^{[7]}$.

The mixture of urea, HA, FA, TSP and MOP had a greatest effect reducing ammonia loss up to hundred percent and also retained exchangeable ammonium and available nitrate in the soil compared to urea without additives. Zero loss of ammonia related to the low $\mathrm{pH}$ found in the study that also confirms the work of Delaune and Patrick ${ }^{[19,20]}$ that urea hydrolyzes slowly when soil $\mathrm{pH}$ is less than 5.5 and lasted until it moves away from the acidified soil ${ }^{[5,19]}$. The amendment effectively increased the volume of soil with which urea was mixed and increased the time required for complete hydrolysis $^{[5]}$.

\section{CONCLUSION}

Urea-TSP-MOP-HA, Urea-TSP-MOP, Urea-TSPMOP-FA and Urea-TSP-MOP-Acidified (HA + FA) mixtures significantly reduced ammonia loss by 12.92 , $20.12,29.54$ up to $100 \%$ compared to urea alone. The similar observation was made for soil exchangeable ammonium. Urea-TSP-MOP-FA and Urea-TSP-MOPAcidified (HA + FA) significantly increased soil available nitrate accumulation and the findings were consistent with $\mathrm{pH}$ found in the study. It must be stressed that results obtained in the incubation experiment using an acidic $\left(\mathrm{pH}_{\text {water }} 6.32\right)$ soil of Typic Paleudults (Bekenu Series) may only be applicable to similar acid soils. The outcome of this study may contribute to the improvement of urea N, P and K use efficiency as well as reducing environmental pollution.

\section{ACKNOWLEDGMENT}

The researchers acknowledge the financial support of this research by the Ministry of Higher Education Malaysia.

\section{REFERENCES}

1. Ahmad, A., S. Ismail and S. Bhatia, 2003. Water recycling from Palm Oil Mill Effluent (POME) using membrane technology. Desalination, 157: 87-95. DOI: 10.2225/vol10-issue3-fulltext-7

2. Suhaimi, M. and H.K. Ong, 2001. Composting empty fruit bunches of oil palm. Food and Fertilizer Technology Center, Taipei, Taiwan. http://www.agnet.org/library/eb/505a/

3. O-Thong, S., P. Prasertsan, N. Intrasungkha, S. Dhamwichukorn and N.K. Birkeland, 2008. Optimization of simultaneous thermophilic fermentative hydrogen production and COD reduction from palm oil mill effluent by Thermoanaerobacterium-rich sludge. Int. J. Hydrogen Energy, 33: 1221-1231. DOI: 10.1016/j.biortech.2008.07.036

4. Fan, M.X. and A.F. Mackenzie, 1993. Urea and phosphate interactions in fertilizer microsites: Ammonia volatilization and $\mathrm{pH}$ changes. Soil Sci. Soc. Am. J., 57: 839-845. DOI: 10.1007/BF00749946

5. Siva, K.B., H. Aminuddin, M.H.A. Husni and A.R. Manas, 1999. Ammonia volatilization from urea as affected by tropical-based palm oil palm effluent (pome) and peat. Commun. Soil Sci. Plant Anal., 30: 785-804. DOI: $10.1080 / 00103629909370246$ 
6. Stumpe, J.M., P.L.G. Vlek and W.L. Linday, 1984. Ammonia volatilization from urea and urea phosphates in calcareous soils. Soil Sci. Soc. Am. J., 48: 921-926.

http://soil.scijournals.org/cgi/content/abstract/48/4/ 921

7. Ahmed, O.H., M.H.A. Husni, A.R. Anuar and M.M. Hanafi, 2006. Effects of urea, humic acid and phosphate interactions in fertilizer microsites on ammonia volatilization and soil ammonium and nitrate contents. Int. J. Agric. Res., 1: 25-31. DOI: 10.3923/ijar.2006.25.31

8. Ahmed, O.H., M.H.A. Husni, A.R. Anuar and M.M. Hanafi, 2006. Reducing ammonia loss from urea and improving soil-exchange ammonium retention through mixing triple superphosphate, humic acid and zeolite. Soil Use Manage., 22: 315-319. DOI: $10.1111 / \mathrm{j} .1475-2743,2006.00040 . \mathrm{x}$

9. Brady, N.C. and R.R. Weil, 2002. The Nature and Properties of Soils. Prentice Hall, ISBN: 0130167630, pp: 960.

10. Cheftez, B., P.G. Hatcher, Y. Hadar and Y. Chen, 1996. Chemical and biological characterization of organic matter during composting of municipal solid waste. J. Environ. Q., 25: 776-785. http://jeq.scijournals.org/cgi/reprint/25/4/776

11. Tan, K.H., 2005. Soil Sampling, Preparation and Analysis. 2nd Edn., CRC Press, Taylor and Francis Group. Boca Raton, Florida, USA., ISBN: 0-84933499-3, pp: 154-174.

12. Stevenson, F.J., 1994. Humus Chemistry: Genesis, Composition and Reactions, 2nd Edn. John Wiley and Sons, New York, ISBN: 0471594741, pp: 512.

13. Ahmed, O.H., M.H.A. Husni, A.R. Anuar, M.M. Hanafi and E.D.S Angela, 2004. A modified way of producing humic acids from pineapple leaves. J. Sustainable Agric., 25: 129-139. DOI: 10.1300/J064v25n01_10
14. Inbar Y., Y. Chen and Y. Hadar. 1990. Humic substances formed during the composting of organic matter. Soil Sci. Am. J., 54: 1316-1323. http://soil.scijournals.org/cgi/reprint/54/5/1316

15. Keeney, D.R. and D.W. Nelson, 1982. NitrogenInorganic Forms. In: Methods of Soil Analysis, Part 2, Page, A.L., D.R. Keeney, D.E. Baker, R.H. Miller, R. Ellis Jr. and J.D. Rhoades (Eds.). 2nd Edn., Agronomy 9, ASA and SSSA, Madison, WI., ISBN: 0891180729.

16. SAS., 2001. SAS/STAT Software. SAS Institute, NC., ISBN: 1580258506, pp: 352.

17. Paramanathan, S., 2000. Soils of Malaysia: Their Characteristics and Identification. Academy of Sciences Malaysia, Kuala Lumpur. ISBN: 9839445065

18. Tan, K.H., 2003. Humic Matter in Soil and the Environment: Principles and Controversies. Mercel Dekker, Inc., New York, ISBN: 0824742729, pp: 408.

19. Delaune, R.D. and W.H. Jr. Patrick, 1970. Urea conversion to ammonia in waterlogged soil. Soil Sci. Soc. Am. Proc., 34: 603-607. http://soil.scijournals.org/cgi/content/abstract/34/4/ 603

20. Ahmed, O.H., M.H.A. Husni and H. Aminuddin, 2006. Ammonia volatilization and ammonium accumulation from urea mixed with zeolite and triple superphosphate. Acta Agric. Scandinavica Section B-Soil Plant Sci., 58: 182-186. DOI: 10.1080/09064710701478271 